\title{
Intrauterine growth and intelligence within sibling pairs: findings from the Mater-University study of pregnancy and its outcomes
}

\author{
Debbie A Lawlor, William Bor, Michael J O'Callaghan, Gail M Williams, Jake M Najman
}

J Epidemiol Community Health 2005;59:279-282. doi: 10.1136/jech.2004.025262

\begin{abstract}
Objective: To examine the association between intrauterine growth and intelligence.

Design: Population based birth cohort study of sibling pairs born within a maximum of three years of each other.

Setting: Mater-University women and children's hospital, Brisbane, Australia.

Participants: 235 (470 children) sibling pairs.

Results: Among one randomly selected sibling from each pair verbal comprehension at age 5 , general intelligence at age 14 , and reading ability at age 14 increased linearly with increasing gestational age and sex standardised birth weight $z$ scores. With adjustment for maternal age, race, and smoking during pregnancy, birth order, family income, and parental education the associations with verbal comprehension at age 5 and general intelligence at age 14 remained, whereas the association with reading ability at age 14 was attenuated to the null. Within sibling pairs, differences in intrauterine growth were positively associated with differences in verbal comprehension at age 5 (test score difference per one unit difference in birth weight $z$ score $=1.52(0.11$ to 3.26)) and general intelligence at age 14 (1.09 (0.01 to 2.18)), but not with reading ability at age 14 .

Conclusions: Socioeconomic position or other fixed maternal characteristics do not seem to explain the positive association between intrauterine growth and childhood intelligence.
\end{abstract}

B irth weight is positively associated with intelligence in later life, but the mechanisms for this association are unclear. $^{1-6}$ As maternal characteristics such as her genotype, earlier life nutrition, education, and socioeconomic position are concordant for sibling pregnancies, within sibling analyses are a way of controlling for such characteristics. In one study there was no association between birth weight and intelligence within siblings. ${ }^{7}$ However, a second sibling study found that within male sibling pairs the association between birth weight and intelligence remained suggesting that, for males at least, the association between birth weight and intelligence was not explained by fixed maternal characteristics. $^{8}$ Three within twin pair studies ${ }^{9-11}$ are difficult to interpret. In the largest twin study to date, there was no association within monozygotic twin pairs $(n=81)$, leading the authors to suggest that genetic factors explained the association. ${ }^{11}$ However, two other studies of $25^{9}$ and $27^{10}$ monozygotic twin pairs found that within twin pairs birth weight differences were positively associated with intelligence differences. These conflicting results warrant further investigation.

\section{METHODS}

The Mater-University study of pregnancy and its outcomes (MUSP) is a population based prospective study of women, and their offspring, who received antenatal care at a public hospital in Brisbane between 1981 and $1984 .{ }^{12}$ The birth cohort included 520 sibling pairs who were live singleton births and left hospital alive with their biological mothers. Of these there were 235 pairs (470 individuals) with measures of intelligence and all covariates at age 5 and 14. Children with known cerebral defects did not undergo intelligence tests. The attrition among siblings was similar to that among the whole cohort ${ }^{12}$ and mean birth weight, maternal age, and family income did not differ between included siblings and those without data or lost to follow up. Siblings who could not be included were more likely to have mothers who had smoked throughout both pregnancies (43\% compared with $31 \%, \mathrm{p}=0.005)$.

A sex and gestational age (in weeks) standardised birth weight $\mathrm{z}$ score was computed to give a measure of intrauterine growth. Intelligence at age 5 was assessed using the revised Peabody picture vocabulary test (PPVT-R), a measure of verbal comprehension. ${ }^{13}$ Intelligence at age 14 was assessed using youth scores on Raven's standard progressive matrices, which measures general intelligence $(g)^{14}$ and the wide range achievements test version 3 (WRAT3), a test of reading ability. ${ }^{15}$ Tests were age standardised in six-monthly intervals to have mean (SD) values of 100 (15).

Our analytical approach was identical to that of a previous study. ${ }^{8}$ One sibling from each pair was selected at random (one sibling sample) and multiple linear regression was used to assess the association between intrauterine growth and intelligence in this group. Multiple linear regression was used to assess the within sibling pair association. In these analyses the dependent variable was difference in intelligence and the explanatory variable difference in birth weight $\mathrm{z}$ score. In these models we controlled for between sibling differences in age at the time of intelligence testing, differences in maternal age at birth, birth order, and family income by including differences for continuous variables as covariates in the models and for family income including indicator variables that indicated whether the pairs were high/high, low/low, high/low, or low/high income. ${ }^{8}$ All analyses were conducted using Stata version 8.0 (Stata, TX).

\section{RESULTS}

There were high levels of agreement between siblings for maternal education $(91 \%$ agreement, $\kappa$ statistic $=0.93$, $\mathrm{p}<0.001)$, paternal education $(87 \%, \kappa=0.88, \mathrm{p}<0.001)$, and maternal smoking throughout pregnancy $(97 \%, \kappa=0.95$, $\mathrm{p}<0.001)$. Agreement for family income during the year of pregnancy was lower $(73 \%, \kappa=0.35, \mathrm{p}<0.001)$. The mean (SD) age difference between the siblings was 1.7 (0.4) years. Mean (SD) birth weight was 3343.6 (484.4) grams for females and 3432.6 (526.4) grams for males. Mean (SD) gestational age was 39.4 (1.7) weeks, with a range 
Table 1 Pearson's pair-wise correlation coefficients between measures of intelligence and intrauterine growth in sibling pairs $(n=235)$

\begin{tabular}{|c|c|c|c|c|c|c|c|c|}
\hline & $\begin{array}{l}\text { PPVT-R } \\
\text { age } 5 \\
\text { sib } 1\end{array}$ & $\begin{array}{l}\text { PPVT-R } \\
\text { age } 5 \\
\text { sib } 2\end{array}$ & $\begin{array}{l}\text { Raven's } \\
\text { age } 14 \\
\text { sib } 1\end{array}$ & $\begin{array}{l}\text { Raven's } \\
\text { age } 14 \\
\text { sib } 2\end{array}$ & $\begin{array}{l}\text { WRAT3 } \\
\text { age } 14 \\
\text { sib } 1\end{array}$ & $\begin{array}{l}\text { WRAT3 } \\
\text { age } 14 \\
\text { sib } 2\end{array}$ & $\begin{array}{l}\text { Birth weight for sex } \\
\text { and gestational age } \\
\text { z score sib } 1\end{array}$ & $\begin{array}{l}\text { Birth weight for sex } \\
\text { and gestational age } \\
\text { z score sib } 2\end{array}$ \\
\hline PPVT-R age 5 sib 1 & 1 & & & & & & & \\
\hline PPVT-R age 5sib 2 & 0.52 & 1 & & & & & & \\
\hline $\begin{array}{l}\text { Raven's SPM age } 14 \\
\text { sib } 1\end{array}$ & 0.39 & 0.16 & 1 & & & & & \\
\hline $\begin{array}{l}\text { Raven's SPM age } 14 \\
\text { sib } 2\end{array}$ & 0.24 & 0.35 & 0.30 & 1 & & & & \\
\hline WRAT3 age 14 sib 1 & 0.31 & 0.17 & 0.35 & 0.20 & 1 & & & \\
\hline WRAT3 age 14 sib 2 & 0.13 & 0.17 & 0.11 & 0.29 & 0.38 & 1 & & \\
\hline $\begin{array}{l}\text { Birth weight for sex } \\
\text { and gestational age } \\
\text { z score sib } 1\end{array}$ & 0.36 & $0.09^{*}$ & 0.27 & -0.10 & 0.25 & $0.06 *$ & 1 & \\
\hline $\begin{array}{l}\text { Birth weight for sex } \\
\text { and gestational } \\
\text { age } z \text { score sib } 2\end{array}$ & $0.08^{*}$ & 0.38 & $0.07^{*}$ & 0.30 & $0.02^{*}$ & 0.21 & 0.47 & 1 \\
\hline
\end{tabular}

28-42 weeks for both sexes. Correlations between siblings for intelligence were weak or modest (table 1).

Among one randomly selected sibling from each pair verbal comprehension at age 5, general intelligence at age 14, and reading ability at age 14 increased linearly with increasing birth weight $\mathrm{z}$ scores (table 2 ). With adjustment for maternal age, race, and smoking during pregnancy, birth order, family income, and parental education the associations with verbal comprehension at age 5 and general intelligence at age 14 remained whereas the association with reading ability at age 14 was attenuated to the null.

Within sibling pairs differences in intrauterine growth were positively associated with differences in verbal comprehension at age 5 (test score difference per one unit difference in birth weight $\mathrm{z}$ score $=1.52(0.11$ to 3.26$))$ and general intelligence at age $14(1.09(0.01$ to 2.18$))$, but not with reading ability at age $14(0.30(-0.68$ to 1.29$))$. Sex specific analyses did not suggest there were any sex differences (all three $p$ values of interaction with sex $>0.7$ ). For example, the difference in the PPVT-R test per one unit difference in birth weight $\mathrm{z}$ score for same sex female sibling pairs $(\mathrm{n}=65)$ was $1.33(-1.61$ to 4.27$)$ and for male sibling pairs $(n=83)$ was $1.48(-1.03$ to 3.55$)$. When analyses were restricted to pairs in which both siblings were born between 36 and 41 weeks of gestation ( $n=228$ pairs) the results did not differ from those presented.

\section{DISCUSSION}

We have found positive associations between intrauterine growth and verbal comprehension at age 5 and general intelligence at age 14, which do not seem to be explained by fixed maternal characteristics. Complete data were available on just $50 \%$ of siblings in the original cohort. Our results would only be biased if the associations in those siblings who could not be included in the analysis were non-existent or in the opposite direction.

Our results are generally consistent with findings of Matte et $a l^{8}$ and with results from within dizygotic twin pairs. ${ }^{11}$ Unlike Matte $e t \mathrm{al}^{8}$ we found no evidence of a sex difference in the within sibling pairs association. Although one within twin study suggested that the association between birth weight and intelligence was attributable to genetic factors, ${ }^{11}$ the small numbers in all three twin studies ${ }^{9-11}$ to date and differences in their findings suggest that further evidence is required before one can conclude that this association is genetic.
Our results suggest that socioeconomic position or other fixed maternal factors do not fully explain the association between intrauterine growth and intelligence. Maternal diet during pregnancy, use of medications, placentation and therefore fetal nutrition will vary from pregnancy to pregnancy and may explain the association.

\section{CONTRIBUTORS}

DAL developed the study aim and design. WB, JMN, MJO, GMW, set up and are responsible for the conceptual development and continued management of the Mater-University Study of Pregnancy and its outcomes. DAL undertook the analysis and wrote the first draft of the paper. All authors contributed to the final version of the paper.

\section{ACKNOWLEDGEMENTS}

We are grateful to all participants in the study. Greg Shuttlewood, University of Queensland helped with data management for the study.

\section{Authors' affiliations}

D A Lawlor, Department of Social Medicine, University of Bristol, UK W Bor, M J O'Callaghan, Child Development and Rehabilitation Services, Mater Children's Hospital, Brisbane, Australia

G M Williams, J M Najman, School of Population Health, University of Queensland Medical School, Brisbane, Australia

J M Najman, School of Social Science, University of Queensland, Brisbane, Australia

Funding: the core study is funded by the National Health and Medical Research Council of Australia. D A Lawlor is funded by a UK Department of Health Career Scientist Award. The views expressed in this publication are those of the authors and not necessarily those of any funding body. Conflicts of interest: none declared.

Correspondence to: Dr D A Lawlor, Department of Social Medicine, University of Bristol, Canynge Hall, Whiteladies Road, Bristol BS8 2PR, UK; d.a.lawlor@bristol.ac.uk

Accepted for publication 19 August 2004

\section{REFERENCES}

1 Breslau N, Chilcoat H, DelDotto J, et al. Low birth weight and neurocognitive status at six years of age. Biol Physchiatry 1996;40:389-97.

2 Sorensen HT, Sabroe S, Olsen J, et al. Birth weight and cognitive function in young adult life: historical cohort study. BMJ 1997;315:401-3.

3 Richards M, Hardy R, Kuh D, et al. Birthweight and cognitive function in the British 1946 birth cohort: longitudinal population based study. BMJ 2001;322: 199-203.

4 Shenkin SD, Starr JM, Pattie A, et al. Birth weight and cognitive function at age 11 years: the Scottish Mental Survey 1932. Arch Dis Child 2001;85:189-97. 


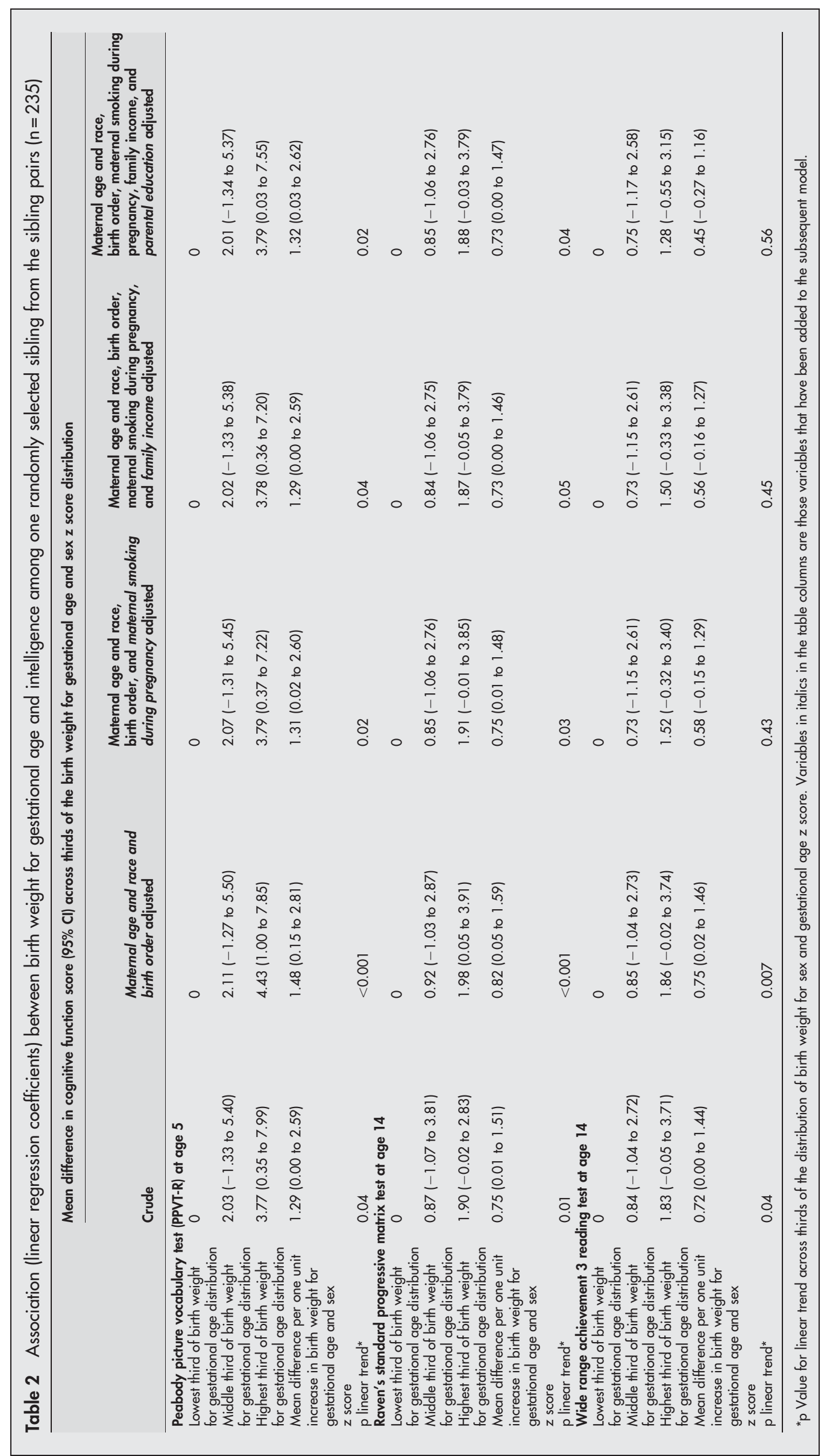


5 Jefferies BJMH, Power C, Hertzman C. Birth weight, childhood socioeconomic environment, and cognitive development in the 1958 British birth cohort study. BMJ 2002;325:305-8

6 Osler M, Andersen A-M N, Due P, et al. Socioeconomic position in early life birth weight, childhood cognitive function and adult mortality. A longitudina study of Danish men born in 1953. J Epidemiol Community Health 2003; 57:681-6.

7 Record RG, McKeown T, Edwards JH. The relationship of measured intelligence to birth weight and duration of gestation. Ann Hum Genet Lond 1969;33:71-9.

8 Matte TD, Bresnahan M, Begg MD, et al. Influence of variation in birth weight within normal range and within sibships on IQ at age 7 years: cohort study. BMJ 2001;323:310-14.

9 Scarr S. Effects of birth weight on later intelligence. Soc Biol 1969;16:249-56.
10 Willerman L, Churchill JA. Intelligence and birth weight in identical twins. Child Dev 1967;38:623-9.

11 Boomsma DI, van Beijsterveldt CE, Rietveld MJ, et al. Genetics mediate relation of birth weight to childhood IQ. BMJ 2001;323: 1426.

12 Najman JM, Aird R, Bor W, et al. The generational transmission of socioeconomic inequalities in child cognitive development and emotional health. Soc Sci Med 2004;58:1147-58.

13 Dunn LM, Dunn LM. Peabody picture vocabulary test revised. New York: American Guidance Service, 1981

14 de Lemos MM. Standard progressive matrices, Australian manual. Victoria: The Australian Education Council for Research, 1989.

15 Wilkinson GS. Wide range achievement test (WRAT3) administration manual. Wilmington, DE: Wide Range, 1993. 